\title{
ASPECTOS MORFOESTRUTURAIS DO RELEVO NA REGIÃO NORTE DA CIDADE DE MANAUS E SUAS INFLUÊNCIAS NA DINÂMICA DO AQUÍFERO ALTER DO CHÃO
}

\author{
MORPHOSTRUCTURAL ASPECTS OF THE RELIEF IN THE \\ NORTHERN MANAUS CITY REGION AND ITS INFLUENCES ON \\ THE DYNAMICS OF THE ALTER DO CHÃO AQUIFER
}

\begin{abstract}
João da Silva Carvalho
Universidade Federal do Amazonas (UFAM) - Programa de Pós-Graduação em Clima e Ambiente (CLIAMB/INPA/UEA) - Av. Rodrigo Octávio Jordão Ramos, 6200 - Campus UIniversitário, Setor Norte - Coroado - CEP 69077-000, Manaus (AM) - Telefone: (92) 3305-2817/2818

E-mail: jscarvalho@ufam.edu.br

$\begin{aligned} \text { Javier Tomasella } & \text { Tomas }\end{aligned}$

Centro de Ciência do Sistema Terrestre do Instituto Nacional de Pesquisas Espaciais-MCT - Rodovia Presidente Dutra, km 39 - CEP 12630-000 - Cachoeira Paulista, SP - Brasil - Caixa-Postal: 01 Telefone: (12) 31868461 Fax: (12) 31012835 E-mail: javier.tomasella@cptec.inpe.br
\end{abstract}

\section{Informações sobre o Artigo}

Data de Recebimento:

$13 / 06 / 2013$

Data de Aprovação:

01/10/2013

\section{Palavras-chave:}

Feições geomorfológicas; alinhamentos tectônicos; fluxo subterrâneo.

\section{Keywords:}

Geomorphological features; tectonic lineaments; underground flow.

\begin{abstract}
Resumo
A área de estudo está localizada a norte da cidade de Manaus, entre as coordenadas de $2^{\circ} 00^{\prime}$ e $3^{\circ} 00^{\prime}$ de latitude sul e 59 $30^{\circ}$ e $60^{\circ} 30^{\prime}$ de longitude oeste, envolvendo porções dos municípios de Manaus, Rio Preto da Eva e Presidente Figueiredo. Essa porção territorial exibe predominantemente sedimentos da Formação Alter do Chão, de idade neocretácea, representada por materias clásticos e pelíticos que foram depositados em depressões tectônicas originadas durante a abertura do Oceano Atlântico. Atualmente esses terrenos são afetados por diversos lineamentos estruturais, com direções preferenciais NE-SW a NW-SE, a exemplo dos lineamentos Rio Preto da Eva e Rio Urubu, que condicionam as trajetórias dos respectivos rios. Esta unidade estratigráfica hospeda o sistema aquífero Alter do Chão, que é o mais importante manancial de águas subterrâneas dessa região. O trabalho consistiu de análises sobre produtos temáticos (mapas de drenagem, declividade e curvas de nível) gerados por processamento de imagens SRTM, por meio dos softwares ArcGis e Global Mapper, com apoio de referências geológicas, hidrogeológicas e geodésicas obtidas nos banco de dados da CPRM e IBGE, respectivamente. A morfologia do relevo, fortemente dissecado pela drenagem, está condicionada às direções dos alinhamentos estruturais, além de destacar outras feições importantes, como o escalonamento do relevo em níveis diferenciados, a declividade da superfície (com aclive no sentido da borda da bacia), e a assimetria das redes de drenagem, que são reflexos do processo de basculamento de blocos, identificados pelo parâmetro Fator de Assimetria. As porções mais impactadas dessa região correspondem às áreas de expansão da fronteira urbana norte da cidade de Manaus, porções urbanas e periurbanas do município de Rio Preto da
\end{abstract}


Eva, áreas de ocupações (comunidades rurais), áreas de transformação de floresta em pastagens e cultivos, áreas submetidas a atividades de mineração, assim como as faixas de ocupação marginais das rodovias e drenagens principais. A declividade topográfica e a geometria do pacote sedimentar da Formação Alter do Chão, que é mais espesso $(230 \mathrm{~m})$ no limite norte da cidade de Manaus e se adelgaça no sentido da borda norte da bacia, favorece o fluxo migratório das águas subterrâneas, que tem sentido principal para SW, sendo influenciado pela estruturação geral. O alto grau de preservação da floresta, associado ao baixo grau de uso do solo, somado ainda ao fato de que grande parte da área está compreendida em área de proteção ambiental, favorece o processo de infiltração da água no solo e, por conseqüência, à recarga do aquífero Alter do Chão.

\begin{abstract}
The area covered by this work lies in the region north of the Manaus city, between the coordinates $2^{\circ} 00^{\prime}$ and $3^{\circ} 00^{\prime}$ south latitude and 59 $30^{\prime}$ and $60^{\circ} 30^{\prime}$ west longitude, involving parts of the municipalities of Manaus, Rio Preto da Eva an Presidente Figueiredo. This area exhibits predominantly sedimentary rocks of the Alter do Chão Formation, represented by fluviallacustrine, clastic and pelitic rocks, from the Late Cretaceous, which were deposited in tectonic depressions originated during the opening of the Atlantic Ocean. Currently these lands are affected by various structural lineaments with NE-SW to NW main directions, the example of Rio Preto da Eva and Urubu river lineaments. This stratigraphic unit hosts the Alter do Chão aquifer system, which is the most important source of groundwater in the region. The work consisted of analysis of thematic products (maps of drainage, slop and topographic contour) generated by SRTM image processing, using the ArcGis and Global Mapper softwares, with support from geological, hydrogeological and geodetic references obtained from the data bank of the CPRM and IBGE, respectively. The topography is heavily dissected by drainage, strictly subject to the directions of structural alignments, and highlights other important features such as staggered pattern at different levels, the slope of the surface (with slope towards the edge of the basin) and the asymmetry of drainage basins, which reflect the process of tilting blocks, identified by factor asymmetry parameter. The most impacted portions of the region correspond to urban boundary expansion areas north of the Manus City, urban and peri-urban parts of the Rio Preto da Eva city, rural communities, transformation of forest areas in pastures and crops, areas subject to mining activities, as well as the marginal occupation of highways and main drains. The topographic gradient and the geometry of sedimentary package of Alter do Chão Formation, which is thicker (230 m) at the northern limit of the city of Manaus and tapering towards the northern border of the basin, favors the migratory flow of groundwater, which has main SW direction, being influenced by structuring. The high degree of forest preservation, associated with the low degree of land use, added to the fact that much of the area is included in the area of environmental protection, improve water infiltration and, consequently, recharging of the Alter do Chão aquifer.
\end{abstract}

\section{Introdução}

Este estudo foi realizado em uma área de aproximadamente $12.000 \mathrm{~km}^{2}$, localizada a norte da cidade de Manaus, compreendida entre as coordenadas de $2^{\circ} 00^{\prime}$ e $3^{\circ} 00^{\prime}$ de latitude sul e $59^{\circ} 30^{\prime}$ e $60^{\circ} 30^{\prime}$ de longitude oeste, a qual abrange porções territoriais dos municípios de Manaus, Rio Preto da Eva e Presidente Figueiredo (Figura 1). Nessa região predominam exposições de sedimentos da Formação Alter do Chão, a qual hospeda o sistema aquífero homônimo, com uma reserva estimada em cerca de $32.500 \mathrm{~km}^{3}$ de água (ANA, 2009).

Nesse contexto, este trabalho tem por meta a avaliação dos aspectos geológicos e geomorfológicos e seus efeitos na dinâmica do aquífero Alter do Chão, nessa região, enfatizando os aspectos de recarga desse manancial.

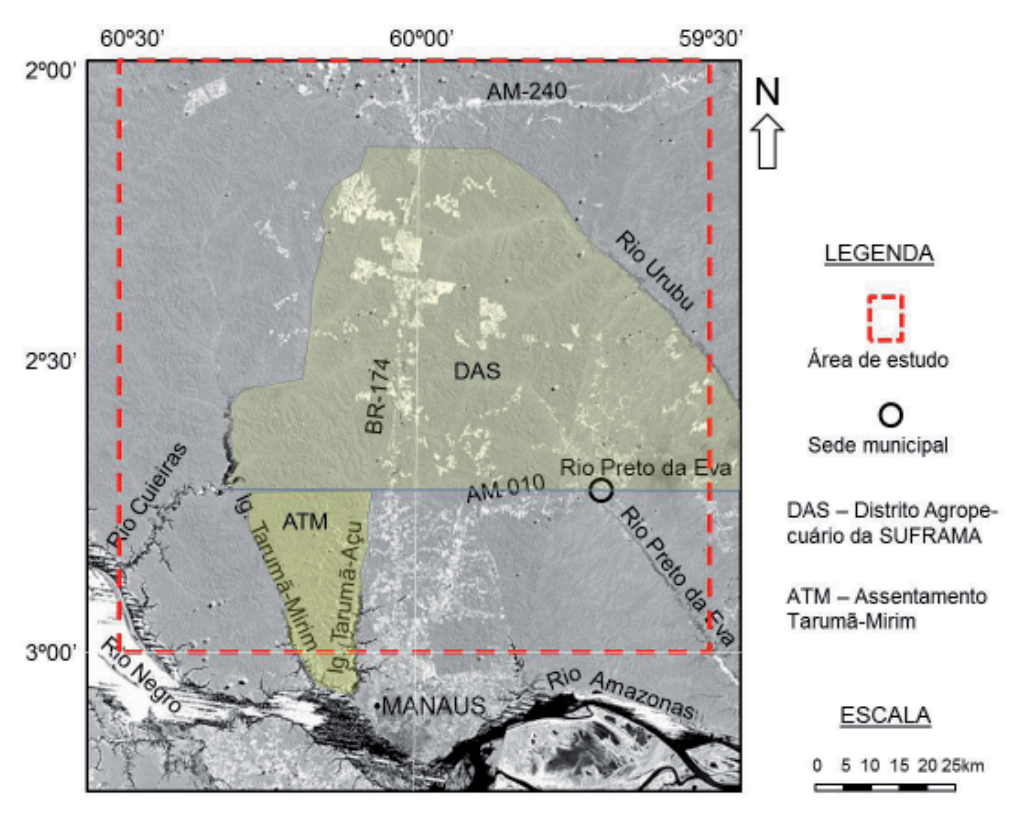

Figura 1 - Imagem de satélite LANDSAT mostrando a localização da área de estudos, onde as manchas claras representam as áreas de ocupação e uso do solo. 


\section{Aspectos geológicos e geomorfológicos}

A área de estudo compreende uma porção da borda norte da Bacia Paleozoica do Amazonas, onde predominam exposições de rochas cretáceas da Formação Alter do Chão, representada por arenitos, siltitos e argilitos, além de sedimentos da Formação Manacapuru, do Grupo Trombetas, ocorrentes em sua porção mais setentrional e constituída por arenitos e pelitos neríticos neossilurianoeodevonianos. A deposição dos sedimentos da Formação Alter do Chão se deu em depressões tectônicas originadas durante o regime distensivo (NW-SE), relacionadas à abertura do Oceano Atlântico (Reis et al., 2006; Cunha et al., 2007). Essas depressões encontram-se limitadas por falhas normais N-S e NNE-SSW (Costa e Hasui, 1997), cujas assinaturas são marcadas por diversos lineamentos estruturais, como exemplo dos lineamentos ManacapuruRio Negro, Rio Preto da Eva e Rio Urubu, com direção NW-SE, os quais condicionam as trajetórias dos respectivos rios (Figura 2).

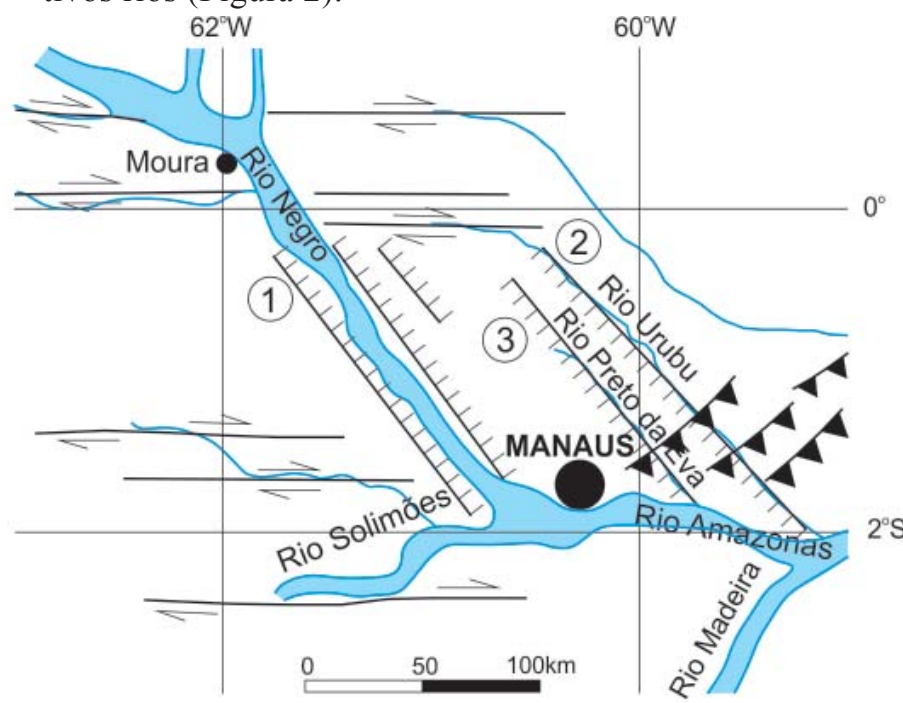

Figura 2 - Principais estruturas neotectônicas da região de Manaus, destacando os lineamentos Rio Negro-Manacapuru (1), Rio Urubu (2) e Rio Preto da Eva, que têm direção NW-SE (baseado em Costa et al., 1999; Silva, 2005)

Geomorfologicamente essa poção territorial está, em grande parte, inserida na unidade Planalto Dissecado Rio Trombetas-Rio Negro, tendo uma pequena faixa de sua porção mais setentrional compreendida no âmbito da unidade Planalto da Bacia Sedimentar do Amazonas (Nascimento et al., 1976; Costa et al., 1978). Os traços no relevo encontram-se condicionados pela estruturação, sugerindo reflexos do arcabouço geológico-estrutural, conforme proposto por Sternberg (1950), Nascimento et al. (1976), Franzinelli e Igreja (1990), Bemerguy (1997), Costa et al. (2001) e Silva (2005).
A hidrografia local é representada fundamentalmente pelas bacias dos rios Cuieiras, Branquinho, Puraquequara, Preto da Eva e Urubu, além dos igarapés Tarumã-Mirim e Tarumã-Açu, tributários dos rios Negro e Amazonas e que drenam sobre sedimentos da Formação Alter do Chão.

O volume médio anual de chuva é da ordem de 2300 $\mathrm{mm}$, distribuído em uma longa estação úmida, que se estende de dezembro a maio e uma estação seca,de agosto a novembro (Leopoldo et al. 1987, apud Luizão e Vasconcelos, 1993).

O relevo dessa região apresenta-se bastante dissecado pela drenagem, configurando feições em formas de platôs, colinas de topos arredondados e vales amplos, de fundo chato, que resultaram em interflúvios estreitos e alongados, obedientes principalmente às direções NW-SE e NE-SW (Silva, 2005).

\section{Métodos de estudos}

para o cumprimento deste trabalho foram realizadas atividades de processamento digital de imagens SRTM (cenas S03W060.htg, S03W061.htg, S04W060 htg e S04W061. htg, obtidas no site: http://dds.cr.usgs.gov/ srtm/version1/ South_America/), por meio dos softwares ArcGis e Global Mapper, que resultaram na elaboração de mapas de drenagem, declividade e curvas de nível.

As referências geológicas necessárias para a construção desses produtos foram obtidas no banco de dados "GEOBANK", da CPRM (disponível no site www.cprm.gov.br), enquanto que os dados topográficos e geodésicos foram obtidos no Sistema Geodésico Brasileiro (IBGE) e as informações hidrogeológicas no Sistema de Informações de Águas Subterrâneas (SIAGAS) da CPRM/Serviço Geológico do Brasil.

A partir da concepção dos produtos digitais, foi realizada uma análise correlativa das mesmas, onde foi possível verificar a influência das feições geológicas e geomorfológicas na dinâmica da água subsuperficial, relacionadas aos aspectos de declividade, características de infiltração e possíveis trajetórias de fluxo subterrâneo.

\section{Caracterização hidrogeológica da Formação Alter do Chão}

\section{Caracterização geral}

A área deste trabalho está inserida no contexto da Província Hidrogeológica Amazonas, que compreende uma sequência sedimentar que vai desde o Paleozoico ao Cenozoico. Rebouças et al. (2006), considerando basicamente os sistemas aquíferos Alter do Chão e Barreiras, estimaram um volume de $32,5 \times 10^{3} \mathrm{~km}^{3}$ de água subterrânea armazenada nessa unidade, o que corresponde a cerca de $28 \%$ da disponibilidade hídrica brasileira. 
De acordo com o Mapa de Domínios/Subdomínios Hidrogeológicos do Brasil (CPRM, 2007), a região norte de Manaus está inserida no âmbito do Domínio Hidrogeológico das Bacias Sedimentares, com dominância do Subdomínio 2Am (Formação Alter do Chão), possuidora de média a muito alta favorabilidade hidrogeológica, devida à elevada relação porosidade/permeabilidade, como também às grandes espessuras de sedimentos. Secundariamente ocorre uma porção do Subdomínio 1Al (Aluviões), relacionado ao Domínio Formações Cenozoicas, possuidoras de porosidade primária com elevada permeabilidade (terrenos arenosos) e vazão resultante dependente da espessura e da razão areia/ argila das mesmas.

\section{O Sistema Aquífero Alter do Chão, na região de Manaus}

A unidade litoestratigráfica de maior potencialidade hidrogeológica da região de Manaus é, indiscutivelmente, a Formação Alter do Chão, que comporta rochas comumente inconsolidadas, dispostas em camadas lenticulares sub-horizontalizadas e afetadas por tectônica recorrente. Essa unidade está estruturada segundo quatro fácies sedimentares (argilosa, arenoargilosa, arenosa e "Arenito Manaus"), organizadas conforme duas sucessões texturais: uma superior, predominantemente pelítica, e outra inferior, de constituição arenosa (Dino et al., 1999; CPRM, 2012), a qual detém as melhores condições hidrogeológicas. $\mathrm{O}$ fácies "Arenito Manaus", ainda que de caráter descontínuo, se comporta como uma rocha selante, de grande importância na preservação ambiental dos estratos subsequentes. Souza e Verma (2006), com apoio em dados de perfis de poços e informações geofísicas (eletrorresistividade) identificaram a existência de interdigitações e descontinuidades laterais nos estratos dessa unidade, ocorrentes a profundidades inferiores a 50 metros.

Essa unidade estratigráfica comporta o Sistema Aquífero Alter do Chão que, na região de Manaus se caracteriza como um manancial do tipo poroso e dominantemente livre, produtor de água de boa qualidade química, com porosidade efetiva de $18 \%$, transmissividade média de $110 \mathrm{~m}^{2} / \mathrm{dia}$, condutividade hidráulica de 2,9x10-2 m/h e velocidade de fluxo muito pequena (da ordem de $2 \mathrm{~cm} / \mathrm{dia}$ ), com gradiente do nível das águas de 0,002 (CPRM, 2012). Ainda conforme essa fonte, o volume de água armazenado na zona saturada do aquífero Alter do Chão, para uma área de $500 \mathrm{~km}^{2}$ na cidade de Manaus, é da ordem de 14,4 $\mathrm{km}^{3}$. Com base em dados da empresa concessionária de águas em Manaus, a produção diária de água subterrânea extraída desse manancial é de $122 \mathrm{mil} \mathrm{m}^{3}$, correspondente a $20 \%$ do abastecimento da cidade (Águas do Amazonas, 2010).
A configuração geométrica admitida para o pacote de sedimentos da Formação Alter do Chão, na região a norte de Manaus, baseada em perfis de poços e relações de contato superficiais, revela um adelgaçamento do pacote no sentido da borda norte da bacia (Figura 3), fazendo contato inferior de modo discordante com rochas mais antigas (pertencentes aos grupos Tapajós, Curuá, Urupadi e Trombetas).

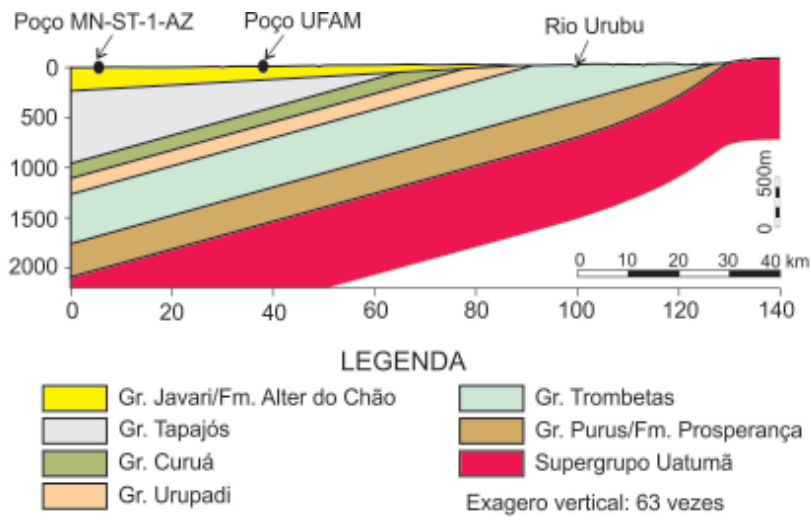

Figura 3 - Seção estratigráfica esquemática da borda norte da Bacia do Amazonas, ao longo da BR-174 (Manaus-km 140) - adaptado de Souza (1974)

Com base em informações do Sistema SIAGAS (CPRM), nessa região a exploração do aquífero Alter do Chão é ainda bastante incipiente, sendo restrita a pouco mais de duas centenas de poços perfurados, dos quais cerca de $50 \%$ não ultrapassam $80 \mathrm{~m}$ de profundidade.

\section{Estudos geomorfológicos}

\section{Caracterização do relevo}

Com base em resultados de estudos anteriores, observações de campo e das análises sobre imagens e produtos temáticos desenvolvidos, verifica-se que o relevo da região a norte da cidade de Manaus encontra-se fortemente dissecado pela drenagem, onde se destacam colinas alongadas e estreitas, com cotas variando entre $50 \mathrm{~m}$ e $150 \mathrm{~m}$, contornadas por vales fechados e estreitos, limitados por vertentes íngremes, onde se encaixa a rede de drenagem. Destacam-se, nessa região, lineamentos de relevo com as seguintes direções: NW-SE, que condicionam os vales dos rios Urubu, Preto da Eva e Puraquequara, além do igarapé Tarumã-Mirim; NE-SW, marcadas pelos vales dos tributários das drenagens principais e trechos do rio Cuieiras; N-S, representada fundamentalmente pelo igarapé Tarumã-Açu, rio Branquinho e trechos do rio Cuieiras, e E-W, de menor frequência, destacada pela porção da foz do igarapé Tarumã-Mirim e do rio Puraquequara e porções do alto curso dos rios Preto da Eva e Urubu (Figura 4). 


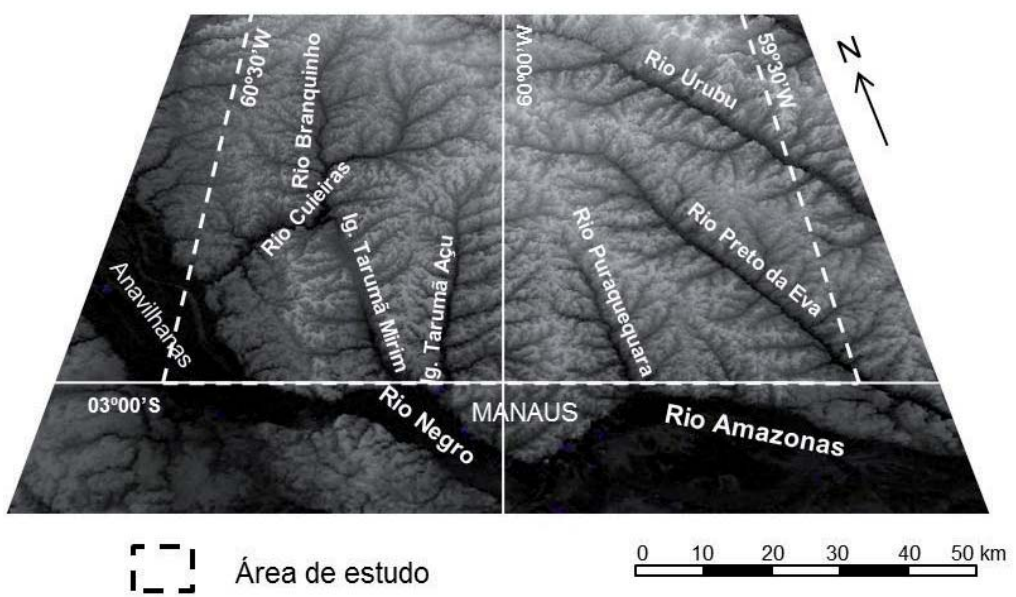

Figura 4 - Modelo 3-D topográfico digital, destacando os principais elementos morfoestruturais da região de estudo (conforme Carvalho, 2012). Linha tracejada representa o contorno da área de estudo.
Outras feições destacadas do relevo, nessa porção, são: (1) o escalonamento do relevo em níveis diferenciados, com cotas variando entre 100 $\mathrm{m}$ no limite norte da cidade de Manaus a $175 \mathrm{~m}$ na porção mais a norte da área (Planalto da Bacia Sedimentar do Amazonas), com forte conotação tectônica, destacada por uma sequência de horsts e grabens, que definem interflúvios alongados (horsts) e vales encaixados (grabens) das drenagens (Figura 5); (2) o forte processo de dissecação do relevo, mais intenso sobre os patamares mais elevados, e (3) a declividade da superfície, ascendente para norte, na zona limítrofe com a unidade Planalto da Bacia Sedimentar do Amazonas.

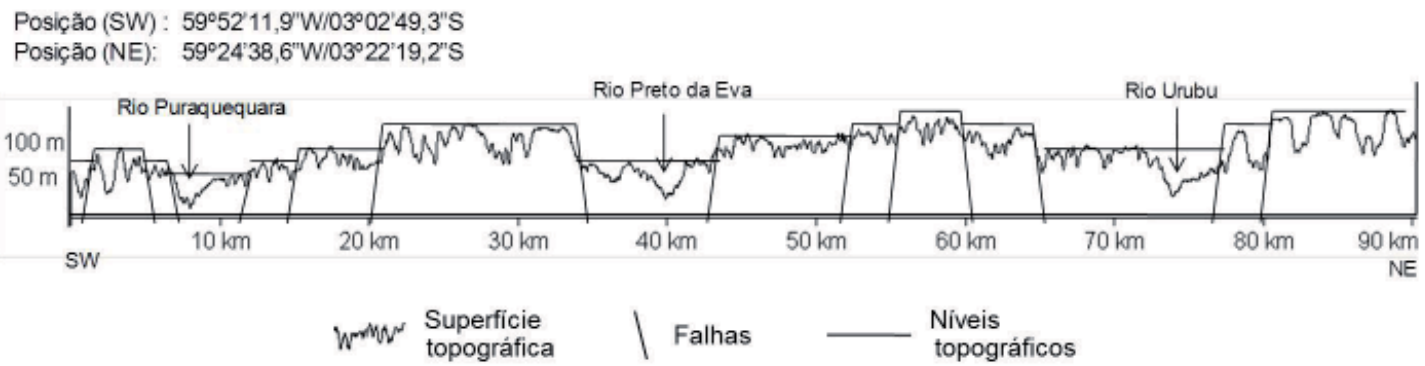

Figura 5 - Perfil topográfico SRTM transversal aos vales dos rios Puraquequara, Preto da Eva e Urubu, destacando, esquematicamente, os efeitos tectônicos na morfologia do relevo.

As falhas definidoras dessas estruturas estão associadas ao trend de direção NW-SE, como reflexo da estruturação do embasamento, as quais influenciam fortemente na morfologia do relevo, com rejeitos evidentes na superfície. Essas feições caracterizam zonas de fragilidades litológicas e, devido aos deslocamentos de blocos, são responsáveis por contatos entre camadas com diferentes graus de permeabilidade, que podem influenciar na dinâmica das águas subterrâneas.

\section{Análise da drenagem}

A rede de drenagem dessa região, representada pelas bacias dos rios Cuieiras, Branquinho, Puraquequara, Preto da Eva e Urubu, e igarapés Tarumã-Mirim e Tarumã-Açu, se configura como um sistema de bacias alongadas, com padrão dominante sub-dendrítico, associado ao condicionamento morfoestrutural da paisagem. A orientação geral dessas drenagens varia de NE-SW a NW-SE, com os tributários alinhados predominantemente nas direções NE-SW e NW-SE, associadas às direções dos principais lineamentos tectônicos (Silva, 2005; Sant'Anna, 2007).
Conforme Gontijo (1999), a tectônica pode promover soerguimentos e abatimentos de áreas ao longo de falhamentos, basculamento de blocos e, desse modo, influenciar no traçado do canal e nos processos de erosão e sedimentação. Um dos resultados do basculamento é a assimetria da bacia de drenagem, manifestada pela dimensão diferenciada dos tributários, entre as margens opostas. A análise dessa característica, associada ao sentido das movimentações tectônicas dos blocos falhados (Keller e Pinter 1996, apud Silva, 2005), é feita a partir do parâmetro Fator de Assimetria (FA), o qual permite avaliar a influência das estruturas subjacentes no comportamento da drenagem. Silva (2005) estudou a geometria das drenagens dessa região e estabeleceu valores de assimetria das principais bacias da região de Manaus, sendo: bacias do igarapé Tarumã-Mirim $(\mathrm{FA}=54)$, do rio Preto da Eva $(\mathrm{FA}=$ $45)$ e do rio Urubu $(\mathrm{AF}=51)$, correspondem a basculamentos de grau fraco (bacias relativamente simétricas), enquanto que os valores determinados para as bacias do igarapé TarumãAçu $(\mathrm{FA}=31)$ e do rio Cuieiras/Branquinho $(\mathrm{FA}=29)$ sugerem basculamento de grau mais forte e, consequentemente, de grandes assimetrias. 


\section{Região norte de Manaus: importante área de recarga do Aquífero Alter do Chão}

No âmbito da área de estudo, as porções mais impactadas por desmatamento e depredação do solo, correspondem às áreas de expansão da fronteira urbana norte da cidade de Manaus, porções urbanas e periurbanas do município de Rio Preto da Eva, áreas de ocupações rurais (comunidades), áreas de transformação de floresta em pastagens e cultivos, áreas onde se desenvolvem atividades de mineração (areais e pedreiras), como também, as faixas de ocupação marginais das rodovias (BR-174 e AM-010 e vicinais) e drenagens principais (rios Cuieiras, Preto da Eva, Puraquequara e Urubu e igarapés Tarumã Açu e Tarumã Mirim). Destacamse, nesse contexto, as áreas de ocupações rurais do Assentamento Tarumã-Mirim (ATM) e Distrito Agropecuário da SUFRAMA (DAS), respectivamente com cerca de $200 \mathrm{~km}$ e $468 \mathrm{~km}$ de estradas vicinais, acessadas a partir das rodovias BR-174 e AM-010. Por concepção, cerca de 80\% da área do DAS é de preservação permanente da mata nativa, e toda a área do ATM está inserida no contexto da Área de Proteção Ambiental (APA) Margem Esquerda do Rio Negro / Setor Tarumã-Açú/Tarumã-Mirim, condições que limitam o desflorestamento. Com base em estudos anteriores (Pinto, 2007 e Nascimento, 2009) e observação visual de imagens de satélite, verifica-se que aproximadamente $80 \%$ da área de abrangência deste trabalho permanece ainda preservados nos seus aspectos naturais, o que compreende volume significativo de área com vegetação natural ou recomposta (Carvalho, 2012).

Em conformidade com a configuração estratigráfica da Formação Alter do Chão, o pacote sedimentar tem espessura da ordem de 230 metros no limite norte da cidade de Manaus (conforme dados do Poço MN-ST-1-AZ, realizado pela Petrobrás) e se adelgaça no sentido da borda da bacia, onde faz limite superficial com sedimentos da Formação Manacapuru (Grupo Trombetas). Ao longo desse trecho (cerca de 94 km de extensão superficial), são identificados grandes alinhamentos estruturais, com direções predominantemente NE-SW e NW-SW, que afetam as camadas sedimentares, configurando feições estruturais tipo grabens e horsts, delimitadas por falhas (normais), os quais controlam os vales das principais drenagens dessa porção, como os rios Cuieiras, Puraquequara, Preto da Eva e Urubu, e igarapés Tarumã Açu e Tarumã Mirim.

Os resultados da análise de assimetria das bacias de drenagem revelam uma predominância de basculamentos de blocos no sentido W a WSW, exceto os blocos rio Urubu e Tarumã Mirim, que inclinam para E, com baixo grau de assimetria (FA de 51 e 54, respectivamente). Observa-se uma tendência de basculamento no sentido do vale rio Negro, o que pode influenciar significativamente no fluxo subterrâneo mais profundo (fluxo de base principal).
O processo de recarga do aquífero, que se inicia com a infiltração da água de precipitação e continua durante as fases de percolação e recarga na interface da zona saturada (superfície freática), culmina com sua descarga nos mananciais superficiais, através do fluxo de base. A topografia da área norte da cidade de Manaus, mais elevada na porção do limite note da Formação Alter do Chão (com a Formação Manacapuru) e deprime para sudoeste (vale do rio Negro), e que envolve um relevo ondulado, ao longo do qual encontram-se instaladas diversas bacias de drenagem, o sistema de fluxo é complexo e envolve sistemas de amplitude local, intermediário e regional. A existência de estruturas geológicas, tais como fraturas, falhas, superfícies de estratificação e estratos impermeáveis, pode ocasionar a acumulação de água em uma camada permeável, ou mesmo sua ascensão através desses condutos, podendo, a depender das características hidrodinâmicas chegar até à superfície, na forma de fonte (surgência) natural. Esse comportamento é comumente encontrado na área de exposição de sedimentos da Formação Nhamundá (Presidente Figueiredo), onde essa estruturação é o principal fator responsável pela formação de cachoeiras.

\section{Conclusões}

A morfologia do relevo na região norte de Manaus é fortemente influenciada pela ocorrência de lineamentos estruturais que afetaram esses terrenos, e que condicionaram a instalação da rede de drenagem, caracterizada por vales alongados nas direções NW-SE e NE-SW, e também influenciam no fluxo de água subterrânea, uma vez que promovem estagnações e alteram algumas características do fluxo, como o potencial hidráulico.

A morfologia do relevo na região norte de Manaus, revela um nítido declive topográfico (desnível da ordem de 120 metros) de norte para sul, no sentido do eixo da bacia, assim como a configuração dos estratos sedimentares da Formação Alter do Chão, que se afunilam para norte, onde se encerram ao contato com rochas arenosas da Formação Manacapuru, do Grupo Trombetas. A sequência inferior (mais arenosa) da Formação Alter do Chão, que sustenta o sistema aquífero homônimo, exerce importância estratégica fundamental, quer como armazenadora e produtora de água de boa qualidade, como também na sua função de manter a perenização de muitos cursos d'água dessa região, relacionados ao processo de descarga subterrânea, associado ao sistema de fluxo local. Com base nessa geometria, e considerando uma faixa de terreno com cerca de $12.000 \mathrm{~km}^{2}$ (área de abrangência deste trabalho), define-se um volume de rochas saturadas da ordem de $900 \mathrm{~km}^{3}$ que, considerando a porosidade efetiva de $18 \%$ (conforme CPRM, 2012), estima-se um volume de água armazenado como da ordem de $162 \mathrm{~km}^{3}$. Esse estoque 
de água subterrânea tem importância estratégica fundamental, devido ao fato de os mananciais superficiais ocorrentes nessa região serem, em sua grande maioria, efêmeros (exceção das drenagens principais).

De acordo com as avaliações de assimetria das bacias de drenagem dessa região, verifica-se que ocorre uma grande simetria nas bacias da porção oriental da área (rios Puraquequara, Preto da Eva e Urubu) e maiores assimetrias (maiores basculamentos) nas bacias da porção oeste (rio Cuieiras/ Branquinho, com sentido para W, e igarapé Tarumã Mirim, com sentido para NE). Nesse contexto, apenas estes últimos podem exercer influência significativa no fluxo subterrâneo, sendo necessário definir esse grau de influência.

$\mathrm{O}$ alto grau de preservação da floresta, associado ao baixo grau de uso do solo, somado ainda ao fato de que grande parte da área está compreendida em área de proteção ambiental, favorece o processo de infiltração da água no solo e, por consequência, a recarga do aquífero.

\section{Agradecimentos}

Agradecemos ao Programa de Pós-Graduação em Clima e Ambiente (INPA/UEA), pela oportunidade de desenvolvimento desse trabalho, à Universidade Federal do Amazonas (UFAM), pelo apoio ao desenvolvimento dos trabalhos de campo e laboratório, ao CNPq pelo apoio financeiro (Processo No 475984/2009-9) e a todos que contribuíram, de forma direta ou indireta para a realização destas tarefas.

\section{Referências bibliográficas}

ÁGUAS DO AMAZONAS. Relatório Anual de Atividades 2009. Manaus, 2010. Disponível em: <www.aguasdoamazonas.com. br>. Acesso em: 03.05.2010.

ANA. Conjuntura dos Recursos Hídricos no Brasil. Agência Nacional de Águas. Brasília, 2009, 204 p. Disponível em: <http:// conjuntura.ana.gov.br/ conjuntura/rh_amazonica. $\mathrm{htm}>$. Acesso em: 12.05.2011.

BEMERGUY, R.L. Morfotectônica e evolução paleogeográfica da região da calha do Rio Amazonas. 1997. 200 f. Tese (Doutorado em Geologia), Centro de Geociências, Universidade Federal do Pará, Belém, 1997

CARVALHO, J.S. Caracterização hidrogeológica da região a norte da cidade de Manaus, com base em informações geofísicas (resistividade elétrica), geológicas e geomorfológicas. 2012. 157 f. Tese (Doutorado em Clima e Ambiente) - Instituto Nacional de Pesquisa da Amazônia/ Universidade do Estado Amazonas, Manaus, 2012

COSTA, J.B.S.; BEMERGUY, R.L.; HASUI, Y.; BORGES, M.S.; FERREIRA JÚNIOR, C.R.P.; BEZERRA, P. E.L.; COSTA, M.L.; FERNANDES, J.M.G. Neotectônica da região Amazônica: aspectos tectônicos, geomorfológicos e deposicionais. Geonomos, Universidade Federal de Minas Gerais, Belo Horizonte, v. 4, n. 2, p. 23-44. 1999.

COSTA, J.B.S., BEMERGUY, R.L., HASUI, Y.; BORGES, M.S. Tectonics and paleogeography along the Amazon river. Journal of South America Earth Sciences, v. 14, p. 335-347. 2001.

COSTA, J.B.S.; HASUI, Y. Evolução geológica da Amazônia. In: COSTA, M.L.; ANGÉLICA, R.S. (Eds) Contribuições à Geologia da Amazônia. Belém, FINEP/SBG- Núcleo Norte, 1997. v. 1, p. 15-90.

COSTA, R.C.R., NATALI FILHO, T.; OLIVEIRA, A.A.B. Geomorfologia da Folha SA.20-Manaus. In: BRASIL. Departamento Nacional da Produção Mineral. Projeto Radambrasil, Folha SA.20-Manaus. Geologia, geomorfologia, pedologia, vegetação e uso potencial da terra. Levantamento de Recursos Naturais, Rio de Janeiro, MME/DNPM, 1978, v. 18, n. 2 , p. $165-244$

CPRM. Mapa de Domínios/Subdomínios Hidrogeológicos do Brasil. CPRM/ Serviço Geológico do Brasil, Rio de Janeiro, 2007. Disponível em: http://www.cprm.gov.br/publique/ cgi/cgilua.exe/sys/start.htm? infoid $=756 \&$ sid=9. Acesso em: 10.08.2010.

CPRM. Relatório Diagnóstico. Aquífero Alter do Chão no Estado do Amazonas. Bacia Sedimentar do Amazonas. Projeto Rede Integrada de Monitoramento das Águas Subterrâneas, Vol. 6. CPRM - SERVIÇO GEOLÓGICO DO BRASIL. Rio de Janeiro, 2012. Versão Digital. Disponível em: <http://www.cprm.gov.br/ publique/media/VOLUME6_Aquifero_Alter_Chão_AM.pdf $>$. Acesso em: 06.05.2013.

CUNHA, P.R.C.; MELO, J.H.G.; SILVA, O. Bacia do Amazonas. In: Boletim de Geociências, Petrobrás, Rio de Janeiro, 2007, v. 15 , n. 2, p. 227-251.

DINO, R., SILVA, O.B.; ABRAHÃO, D. Caracterização palinológica e estratigráfica de estratos cretáceos da Formação Alter do Chão, Bacia do Amazonas. In: Simpósio sobre o Cretáceo do Brasil, 5, 1999, Rio Claro. Anais... Rio Claro, SBG, UNESP, 1999. p. 557-565.

FRANZINELLI, E.; IGREJA, H.L.S. Utilização do sensoriamento remoto na investigação da área do Baixo Rio Negro e Grande Manaus. In: Simpósio Brasileiro de Sensoriamento Remoto, 6, 1990. Manaus. Anais... Manaus, SBG/NO, 1990. v. 3, p. 641-648.

GONTIJO, A.H.F. Morfotectônica do Médio Vale do Rio Paraíba do Sul: Região da Serra da Bocaina, Estados de São Paulo e Rio de Janeiro. 1999. 259 f. Tese (Doutorado em Geologia), Instituto de Geociências e Ciências Exatas, Universidade Estadual Paulista, Rio Claro, 1999.

LUIZÃO, F.J.; VASCONCELOS, H.L. Floresta Tropical Úmida (Manaus). In: Boletim Técnico da CEPLAC, 1993, v. 71, p. 1-13. Disponível em: <www,miniweb.com.br/geografia/artigos/ vegetação/port_site01.pdf.>. Acesso em:12.12.2008. 
NASCIMENTO, D.A., MAURO, C.A.; GARCIA, M.G.L. Geomorfologia da Folha SA.21-Santarém. In: BRASIL. Departamento Nacional da Produção Mineral. Projeto Radambrasil, Folha SA.22-Santarém. Geologia, geomorfologia, pedologia, vegetação e uso potencial da terra. Levantamento de Recursos Naturais. MME/DNPM, Rio de Janeiro, 1976, v. 10, n. 2, p. 131-198.

NASCIMENTO, J.L.A. Uso de Geotecnologias no Monitoramento de Unidades de Conservação: Ocupações Peri-urbanas na APA Margem Esquerda do Rio Negro - Manaus. 2009. 118 f. Dissertação (Mestrado em Ciências Ambientais), Centro de Ciências Ambientais, Universidade Federal do Amazonas, Manaus. 2009.

PINTO, W. H. A. Geoprocessamento aplicado a análise físicoterritorial da área do Tarumã-AM. 2007. 91 f. Dissertação (Mestrado), Universidade Federal do Amazonas, Manaus. 2007.

REBOUÇAS, A.C.; BRAGA, B.; TUNDISI, J.G. Águas doce no Brasil: capital ecológico, uso e conservação. Escrituras Editora, São Paulo, $3^{\text {a }}$. Ed., 2006. 748 p.

REIS, N.J.; ALMEIDA, M.E.; RIKER, S.L.; FERREIRA, A.L. Geologia e Recursos Minerais do Estado do Amazonas. Texto explicativo dos mapas geológico e de recursos minerais do
Estado do Amazonas, 1/1000000, Convênio CPRM/CIAMAAM, Manaus, 2006. 64 p.

SANT'ANNA, C. B. C. Mapeamento da alteração de cobertura vegetal no Distrito Agropecuário da SUFRAMA(DAS) utilizando séries temporais de sensores remotos. 2007. 75 f. Dissertação (Mestrado), Universidade Federal do Amazonas, Manaus. 2007.

SILVA, C.L. Análise da tectônica cenozóica da região de Manaus e adjacências. 2005. 282 f. Tese (Doutorado em Geologia), Instituto de Geociências e Ciências Exatas, Universidade Estadual Paulista, Rio Claro. 2005.

SOUZA, L.B.; VERMA, O.P. Mapeamento de aqüíferos na cidade de Manaus/AM (zonas norte e leste) através de perfilagem geofísica de poço e sondagem elétrica vertical. Revista de Geologia, Universidade Federal do Ceará, Fortaleza, v. 19, n. 1, p. 111-127. 2006.

SOUZA, M.M.. Perfil Geológico da BR174 (Manaus-Boa Vista) no trecho: Manaus - Serra do Abonari. In: Congresso Brasileiro de Geologia, 28, 1974, Porto Alegre, Anais do... Porto Alegre, SBG, 1974, p. 29-33.

STERNBERG, H.O.R. Vales tectônicos na planície amazônica?. Revista Brasileira de Geografia, v. 12, n. 4, p. 3-26. 1950. 